\title{
Neoproterozoic-Paleozoic Redox- Sensitive Trace Metal Records: Oxygenation, Not As We Know It
}

\author{
StOCKEY, R.G. ${ }^{1 *}$, SPERLING, E.A. ${ }^{1}$, FARRELL, U.C. ${ }^{2}$, \\ PLANAVSKY, N.J. ${ }^{3}$, SGP TRACE METAL WORKING \\ GROUP
}

${ }^{1}$ Dept. of Geological Sciences, Stanford University, Stanford, CA (*correspondence: rstockey@stanford.edu)

${ }^{2}$ Geology, Trinity College, Dublin, Dublin, Ireland

${ }^{3}$ Dept. of Geology and Geophysics, Yale University, New Haven, CT

It is widely believed that Earth's oxygenation proceeded in two steps, with the second occurring in the late Neoproterozoic. Records of redox-sensitive trace metals (RSMs) in anoxic shales are one of the strongest lines of evidence for a Neoproterozoic oxygenation event, where increased RSM concentrations are interpreted to represent a decrease in the proportion of seafloor area covered by reducing sinks. Here, we present machine learning analyses of the large dataset of geochemical data and associated geological context information assembled by the Sedimentary Geochemistry and Paleoenvironments Project. Contrary to previous analyses, we show that (when statistically deconvolved from other geochemical and geological context data) there was no stepwise increase in Mo or $U$ concentrations until the Devonian. Our analyses do, however, suggest that there was a stepwise increase in shale total organic carbon (TOC) concentrations around the EdiacaranCambrian boundary.

The lack of change in redox-sensitive metal records therefore contrasts with traditional proxy evidence for a Neoproterozoic shift in the marine redox landscape. However, given links between primary productivity, organic carbon burial, and Earth system oxygenation, the substantial TOC increase likely indicates an atmospheric oxygenation event around the Ediacaran-Cambrian boundary. Accepting this, other biogeochemical processes must therefore have buffered marine Mo-U concentrations despite surface oxygenation. Concomitant changes in productivity and/or reorganization of the seafloor redox landscape are likely mechanisms for maintaining constant global trace metal burial rates. We combine a stochastic Mo-U mass balance approach with geological carbon cycle modeling to quantitatively constrain the magnitude of Earth surface oxygenation across the Ediacaran-Cambrian boundary, and evaluate processes buffering the marine trace metal inventory. 